\title{
Analysis of Quality Control of Professional Training Teaching Reform
}

\author{
Ruili Zhang \\ Naval Aviation Engineering College Qingdao Campus \\ Qingdao, China \\ zrlhao@163.com \\ Xinhua Wang \\ Naval Aviation Engineering College Qingdao Campus \\ Qingdao, China
}

\author{
Yang Gao \\ Naval Aviation Engineering College Qingdao Campus \\ Qingdao, China \\ huangkui@163.com \\ Ping Fang \\ Naval Aviation Engineering College Qingdao Campus \\ Qingdao, China
}

\begin{abstract}
This paper discusses problems existing in the training for professionals of quality control and analyzes the gap between the training and the combat teaching according to the actual teaching situation in colleges and the reform of the combat teaching. Owing to my rich experience in teaching, I put forward some effective solutions to the mentioned problems in many several aspects such as teaching resources, teaching mode, teaching team construction and so on. Indeed, these solutions can be effective and useful for the teaching of the same subject or other subjects in other colleges.
\end{abstract}

Keywords-combat; quality control speciality; post office education

\section{INTRODUCTION}

With the further development of combat teaching, traditional education form cannot meet the requirements of the current demands of military struggle preparation. With the purpose of promoting the teaching environment highly close to combat and making the training content meet the requirements of combat, all kinds of training methods should be close to combat to cultivate talents.

At present, there exist some problems in current combat teaching development and implementation of quality control specialty. These problems are not only in this subject, but also in the process of reform of many professional and many colleges and universities. For example, those may be reflected in the concept in practice, the pursuit of security and stability, fear to use the idea of innovation and difficult courses and so on. A lot of conservative problems hindered in the establishment of the combat training as our teaching content pertinence is not strong and the gap between curriculum and the combat demand is large[1].

\section{EXISTING PROBLEMS UNDER THE BACKGROUND OF COMBAT TRAINING}

According to the past student feedback and the actual demand of the reform in present colleges and universities as well as under the background of combat, the professional training has the following problems:

\section{A. Basic conditions of combat teaching is weak}

It is obvious that the combat teaching is highly relative to the requirement of teaching conditions. However, when teaching needs to extend to the troops, the related teaching facilities are insufficient and the existing teaching content resource is not mature enough, thus lead to the limited combat teaching. Teaching data should be update timely to support laboratory construction lag, information network, electronic teaching, training venues, security and other supporting facilities which have larger gap with actual needs of the combat teaching [2].

\section{B. The overall plan of combat teaching is not enough detailed.}

The current training scheme, course standard are less involved in simulation training teaching, or exposed irrational side under the background of the combat. What's more, the relevance among contents of simulation training and teaching of some joint courses is not strong and the organization of cross major organization is not sufficient. Therefore, it is difficult to obtain teaching collaboration and resource sharing. In addition, the professional combat training lacks of practical and useful teaching mode, inspection evaluation standard of actual combat training and teaching. The effectiveness is difficult to control appropriately as there is still a difficulty in teaching quality assessment. For instance, on the one hand, the training for serving military officers in the quality control subject, there are overwhelmed teaching contents about theory and discussion. On the other hand, the schedule for the visit of teaching in some corporations is insufficient, let alone the corporations and the contents in teaching are not intensively related to the original work. Thus, students cannot learn some useful things. In fact, the administration department is responsible to investigate students' learning needs at least three months or half a year previously, and then set up modules in the following semester based on the results from the investigation. The requirements for the construction of modules will be more hard and detailed if we adhere to combat teaching [3]. 


\section{Teaching content resources are relatively insufficient.}

Existing teaching content resources are designed in terms of the original teaching mode, under the condition of combat teaching. Those resources showed are relatively insufficient and need a new evaluation mechanism under the new situation. Both constructing teaching content and developing resources are relatively complex projects which need a lot of intelligence, energy, time, and multi-sectoral coordination[4]. Whereas the existing evaluation mechanism is not enough incentive, teachers consider it is better to develop courses that use several published papers.

\section{Teaching troop strength is weak}

At present most simulation training teaching are still in the initial stage of development and face the same problem to quality control professional training. Teachers not only master specialized curriculum of theoretical knowledge, but also need to learn the computer technology, network technology, information technology or related knowledge. Teachers should use the theory teaching as well as the simulation of the operation of combat model. Technically, theory teaching teachers can also be combat training teachers. Since training effect is affected by a large extent, we lack of teachers with excellent professional skills, hard technology, fathom forces and high comprehensive abilities.

\section{E. Lack of combat teaching atmosphere}

Environment carries college teaching while actual environment of teaching is an important condition to improve the quality of combat teaching and quality control specialty. The professional training is also essential to build a strong combat environment. Nevertheless, actually, the forces lack of war experience since when the new Republic of China has started. A number of theories and cases stream from countries where wars and fights still exist. The combat environment in teaching can only be achieved by imagination and assumption, so it is hard to say whether or not it is useful in the war. To summarize, how to create a teaching environment highly closing to the reality has become an important problem that worth everyone's thinking. We should follow up the rules of cognition as in the process of teaching, we have to make the theory close to the construction and development of the army maintenance management and use appropriate reference to the aviation maintenance, to make the theory concise and easy to understand and to emphasize its application[5].

\section{THE WAYS OF ADVANCING THE COMBAT TEACHING}

The first thing for combat teaching is to solve the problem of curriculum docking with the army mission, adhere to principles what the war need are to be taught, what army needs to be training, Mission of the troops decide ability demand of training object, which decide training target, setting and construction of curriculum system, so we can promote quality professional construction of combat teaching according to the following ways:

\section{A. Unified operation standard of quality control system}

First, we should carry out combat teaching rely on existing quality control system and further study the possible modules. Second, we should select and develop appropriate training contents and forms based on the realistic military training needs and problems. Next, we need to set out targeted and practical courses in order to make the curriculum system adapting to modern war needs and to exert the function of continuing education services troops. In other words, this means that data standard of quality control system should be unified by relevant departments.

\section{B. Further enrich teaching resources of quality control}

We can organization scenario database, case database, item pool through writing textbooks, handouts and practice instructors of simulation combat teaching. Then, we can carry out the construction of network information resources and enrich resources for simulation training to strengthen combat training and teaching. Moreover, the development of electronic teaching materials, network curriculums and multimedia courseware are necessary to achieve goals of collecting native resources of practical experience and major teaching activities, processing, storing and sharing. We ensure that the timeliness and effectiveness of simulation training teaching will be guaranteed through following the real situation of troops and equipment and updating the teaching contents and improving teaching resources in time[6]. Finally, students can be distributed to different activities such as practice for tasks of flight, mechanical days and maintenance in the factory. At the same time, we can take full advantages of military network resources to start network teaching and long-distance teaching actively, to provide intellectual support for troops and to promote the development of simulation training teaching to a higher level.

\section{Innovative of quality control teaching mode}

Apparently, the combat teaching should concentrate on cultivate students qualified to work and outstand the importance of students. Meanwhile, we have to follow the basic rule of the position training education and use quality control system in the practical training and teaching of students' specialty and ability according to the requirements of the military struggle preparation and professional training objectives. However, it is difficult to achieve the desired results in terms of the episodic teaching methods such as problembased and subject teaching method. The simulation and practical teaching should be added into the process of teaching to realize the overall integration. Therefore, we should rely on the existing network platform to provide an environment including more realistic cases and simulation of time and space, and form a type of teaching mode which can support situational creation, inspire thinking, independent learning, exploration, information acquisition, resources sharing, multiple information sharing, interaction, collaboration and communication. To be more specific, this mode is likely to realize fundamental changes of traditional teaching content to make the innovative talent training goal truly implemented and effectively improve the teaching quality and level of combat [7]. We can also use the opportunity to open the creation of 
course schedule in some local colleges to start the research and creation of the course schedule in the military colleges. This measure may be helpful for the serving officers who have desired to study in other colleges but cannot leave because of the heavy work.

\section{Perfecting professional teaching mechanism of quality control}

It is critical for the teaching and research section to establish the appropriate mechanism of operation and quality management of simulation training teaching, standardize the teaching process and supervise each unit of teaching including courses related to standards of the combat teaching, teaching plan, teaching preparation, implement, summarizes and assessment, etc

\section{E. Development of the combat teaching team construction}

As for the construction of teachers' team as well as the opportunity to carry out the teaching and scientific research innovation team, we should select senior professional teachers and frontline teachers as the first combat teaching backbone by measuring their teaching seniority, professional skills and comprehensive quality. When it comes to the construction of research team, we need to combine the middle-aged teachers with the young teachers and make the reasonable arrangement in structure.

Simultaneously, we have to increase the investment for students, expand the ways of teaching and focus on training and teaching for middle-aged and young teachers. For example, either sending teachers to college or providing them exercise in forces is a good way to improve the ability qualified to work of the teachers. Owing to the demand of combat teaching, we introduce specialized personnel from operations forces and build the foundation of talents[8].

As an army college, we must seize the moment and reform unswervingly deeply, explore a new form of education and training in combat conditions. Furthermore, we shall tap high quality education resources from troops to build a sound talent cultivation system including academy education, military training and military personnel training system, and to resolve deep-seated contradictions and problems of national defense and the army construction.

\section{CONCLUSION}

The teaching reform of the post officers in the aspect of combat teaching has become not only an important topic for each teacher, but also the problems faced by colleges and universities to deepen the reform of education and teaching. The fundamental sectors need to have a profound understanding of the spirit of the higher levels to carry out the implementation perfectly. Moreover, the importance of professional quality control officers' responsibility to those in grass-roots units is self-evident. In conclusion, we have to grasp the right direction of practical, create innovation of teaching methods, and make the implementation of teaching process close to the frontier force on the basis of existing conditions. Consequently, we can change the current situation that the education has been lagged behind the construction in forces, and then cultivate more excellent talents.

\section{REFERENCES}

[1] Jianjun Li, Some Thoughts about the Combat Teaching, Journal of Political Work, 2015.01;

[2] Rui Guo, Zhaohui He, Thinking of Strengthen the Construction of Military Simulation Training and Teaching, Journal of the Airforce Institute of Early Warning, June, 2015, pp.216;

[3] Zhisong Ma,Tao Niu, The Course Reform of Army Combat Teaching Research, Continuing Education, 2013.11, pp.65;

[4] Benyao Shu, Discussion of Teaching for War, Journal of Institute of Equipment, 2014.02, pp. 2;

[5] Nan Zhang, Xuefeng Zhang, Xiaojun Yao, Theoretical Research and Innovation Practice of Fine Management of Aviation Equipment Maintenance Support [M], Beijing, National Defense Industry Press, 2014;

[6] Xianjun, Zhou, The Serving Education Should Be the Main body of the Military Academy Education [J], Chinese Military Education, 2004(1);

[7] Jing Liu, Focus on Practical Teaching of Post Education in Military Academies and the Realization of "Personalized" [J], Science and Education, April, 2010;

[8] Xiaoping Zhang, Military Theoretical Course should Vigorously Promote the Combat Teaching [J], Journal of Higher Education Research, 2010, 33(2), pp109. 